Fanum

Sociológico

\section{Forum Sociológico}

Série II

$21 \mid 2011$

Transformação urbana

\title{
Mobilidade metropolitana: níveis de motorização e padrões de sinistralidade pedonal da cidade de Lisboa
}

Victor Meirinhos

\section{(2) OpenEdition \\ Journals}

Edição electrónica

URL: https://journals.openedition.org/sociologico/404

DOI: $10.4000 /$ sociologico. 404

ISSN: 2182-7427

Editora

CICS.NOVA - Centro Interdisciplinar de Ciências Sociais da Universidade Nova de Lisboa

Edição impressa

Data de publição: 1 dezembro 2011

Paginação: 85-94

ISSN: 0872-8380

Refêrencia eletrónica

Victor Meirinhos, «Mobilidade metropolitana: níveis de motorização e padrões de sinistralidade pedonal da cidade de Lisboa», Forum Sociológico [Online], 21 | 2011, posto online no dia 05 setembro 2012, consultado o 31 março 2022. URL: http://journals.openedition.org/sociologico/404 ; DOI: https://doi.org/10.4000/sociologico.404

Este documento foi criado de forma automática no dia 31 março 2022.

(C) CICS.NOVA 


\title{
Mobilidade metropolitana: níveis de motorização e padrões de sinistralidade pedonal da cidade de Lisboa
}

\author{
Victor Meirinhos
}

\section{Introdução}

1 Segundo a Comissão Europeia, o envolvimento em acidentes de viação constitui a primeira causa de morte e internamento hospitalar por parte dos cidadãos da União Europeia com menos de 45 anos de idade. De facto, só no ano de 2008, os acidentes rodoviários foram responsáveis pela perda de 39000 vidas, sendo que os custos socioeconómicos associados ascenderam aos 180 biliões de euros (cerca de $2 \%$ do PIB da UE). O elevado impacto deste fenómeno na sociedade tem despertado uma grande preocupação não só das autoridades europeias bem como de todos os estados-membros, tendo a segurança rodoviária ascendido à categoria de área prioritária de intervenção na União Europeia (European Commission, 2010). Se, numa primeira fase, uma aposta forte da União Europeia para a diminuição do número de acidentes e de vítimas tem permitido atingir resultados positivos na maioria dos estados-membros ${ }^{1}$, com uma redução média na ordem dos $35 \%$ das estatísticas oficiais de sinistralidade, assumindo Portugal nesta luta uma posição de destaque, com uma redução de $50 \%$ dos números da sinistralidade rodoviária no período entre os anos de 2001 a 2009, os dados de sinistralidade evidenciam uma realidade ainda bastante problemática ao nível dos utentes mais frágeis do meio rodoviário: não só dos peões mas também dos restantes utilizadores de meios de transporte suaves (ciclistas, etc.), considerados essenciais para a promoção de uma mobilidade verdadeiramente sustentável

Constituindo um tema transversal a todas as sociedades contemporâneas, em Portugal as autoridades têm procurado incrementar medidas estruturantes de combate à 
sinistralidade em geral, distinguindo-se dois momentos essenciais para a convergência com as políticas europeias. A primeira fase desta intervenção iniciada em 2003 com a elaboração e implementação do Plano Nacional de Segurança Rodoviária visava reduzir em 50\% o número de vítimas mortais e feridos graves até 2010. Já mais recentemente, em 2009, foi lançado um projecto mais ambicioso, a Estratégia Nacional de Segurança Rodoviária, que teria como meta principal, num período de 7 anos, “... colocar Portugal entre os 10 países da UE com mais baixa sinistralidade rodoviária, medida em mortos a 30 dias por milhão de habitantes" (ANSR, 2009).

3 Tendo em conta a abrangência e a complexidade do fenómeno de sinistralidade rodoviária, nomeadamente em países como Portugal, caracterizados por uma elevada incidência de fatalidades nas estradas, consideramos que uma análise deste tema não deverá ser dissociada de uma análise prévia do fenómeno de motorização das sociedades contemporâneas assim como da evolução urbana das grandes áreas metropolitanas. Com efeito, a evolução dos níveis de motorização em diversos países da OCDE tem revelado uma correlação entre um crescimento mais acentuado da motorização e um menor rendimento per capita (como Portugal, Grécia e Irlanda). Sendo de prever a acentuação nas próximas duas décadas do incremento de propriedade de veículos, pelo menos até que se dê a convergência ao nível do rendimento per capita com a média dos países da OCDE (Dargay e Gately, 1998: 127).

4 Neste aspecto específico, várias investigações têm abordado, ao longo das últimas décadas, o fenómeno da motorização associando-o a diversos efeitos na sociedade e nos indivíduos, destacando-se: os impactos profundos da motorização na mobilidade global (Merriman, 2009), os efeitos de uma excessiva automobilização na sociedade urbana e suburbana (Sheller e Urry, 2000), a mobilidade diária e o tempo dispendido para a realização de diferentes tarefas (Vilhelmson, 1999), e o futuro da mobilidade (Schafer e Victor, 2000). Num outro quadrante, e já no que diz respeito ao fenómeno da procura da mobilidade, tem havido uma especial atenção às necessidades de locomoção através do espaço social e a procura e utilização de diversos modelos de transporte, desde o caminhar até aos meios de transporte motorizados. Prevê-se assim que esta procura incessante de mobilidade possa influenciar ainda mais os padrões de mobilidade da sociedade, actualmente organizada e construída numa matriz motorizada por via de uma procura constante de mobilidade e acessibilidade por parte das populações e economias (Freund e Martin, 2007: 37).

5 A existência de uma matriz "profundamente" motorizada decorrente da associação entre a organização social das cidades modernas e a necessidade de espaço estará na origem do conceito de hyperautomobility, caracterizado por excessiva utilização individual do automóvel particular na realização de viagens diárias (em maior número e mais longas), e potencialmente responsável por um processo de fragmentação das comunidades locais, principalmente ao nível das relações humanas baseadas na proximidade, de vizinhança e comunidade. Durante as últimas décadas têm sido lançados diversos alertas quanto aos consideráveis impactos deste modelo de mobilidade sobre a saúde pública das populações urbanas, nomeadamente os decorrentes dos elevados níveis de poluição associados, da obesidade ou da elevada sinistralidade (Freund e Martin, 2007: 38).

6 De um ponto de vista estrutural, a utilização recorrente do automóvel no dia-a-dia das populações surge directamente associada aos novos padrões de organização das grandes metrópoles mundiais, nomeadamente na cidade de Lisboa, local em que as 
exigências de mobilidade e de desenvolvimento das populações residentes na Região de Lisboa e do Vale do Tejo terão produzido um impacto profundo face a importantes condicionantes de ordem estrutural, política, económica e social, que influenciaram não só a estrutura urbana e organizacional das cidades, mas também as vivências e rotinas dos habitantes dos centros urbanos, da periferia urbana e dos concelhos limítrofes (Teixeira, 1993; Salgado, 1999; Serdoura, 2008 e Baptista e Nunes, 2004: 90). Entendemos desta forma que este fenómeno poderá ser desconstruído isolando cada uma das suas dinâmicas, como a saturação do centro urbano das cidades, face a um crescimento e proliferação de actividade industrial ou de serviços, bem como uma necessidade de a população se deslocar entre os novos aglomerados populacionais e os centros urbanos da cidade de Lisboa (Salgado, 1999: 103).

7 Com efeito, os processos de terciarização e expansão urbana que afectaram a Área Metropolitana de Lisboa (AML) nas últimas décadas exacerbaram a forte dualidade ${ }^{2} \mathrm{em}$ termos de acesso a equipamentos, infra-estruturas e serviços entre os habitantes do centro da cidade e os residentes nas suas coroas periféricas. Esta carência por parte das populações mais afastadas do centro da capital terá contribuído para uma elevada procura de mobilidade por parte de indivíduos que, residindo nos concelhos limítrofes da AML, encontrariam na cidade de Lisboa a resposta às suas necessidades mais primárias (Salgueiro, 1997: 181). Notamos assim que, do ponto de vista da estrutura, o crescimento de toda a região metropolitana não deverá ser dissociado da deslocação em massa de residentes para os concelhos limítrofes da AML, movimento também potenciado pelo crescimento das ligações rodoviárias entre as regiões periféricas e o centro da capital (Meirinhos, 2011: 98).

8 Mas muito para além dos impactos directos destes movimentos populacionais, acentuados nas últimas décadas com o crescimento da malha rodoviária na Área Metropolitana de Lisboa, importará analisar os impactos indirectos de uma reorganização populacional em toda a AML, notórios nos elevados níveis de saturação rodoviária na capital portuguesa (em consequência de 2,3 milhões de viagens registadas $^{3}$ na cidade de Lisboa), bem como na elevada percentagem de vítimas graves e mortais ao nível dos condutores, passageiros e peões em toda a Área Metropolitana e em particular no centro de Lisboa. Sobre este último aspecto não poderemos deixar de realçar a elevada representatividade da zona da Baixa de Lisboa, um local onde, consecutivamente, se tem vindo a registar elevados índices de sinistralidade pedonal, representando $11 \%$ de feridos graves e de $28 \%$ de vítimas mortais do total registado ao nível do concelho nos anos de 2006 a 2009 4 (PSP, 2010).

\section{Desenvolvimento da Estrutura Rodoviária na Área Metropolitana de Lisboa: Breve Apontamento Histórico}

9 O processo de expansão urbana e metropolitana, que se terá acentuado nas décadas de 50 a 70 (Salgueiro, 1997: 180), exigiu das autoridades centrais e locais um planeamento regular com recurso a mecanismos de controlo e planeamento urbano. Face a uma necessidade urgente de regulação, foram desenvolvidos os Planos Directores Municipais (instrumentos de gestão territorial que vinculassem todas as entidades públicas e ainda directa e imediatamente as particulares). Este processo teve uma primeira materialização, em 1948, com o Plano Geral de Urbanização e Expansão de Lisboa - 
elaborado por Etienne de Gröer, durante a presidência de Duarte Pacheco. Este plano teria como principal instrumento o zonamento, a divisão do espaço em áreas com diferentes usos às quais se aplicaria uma legislação específica. Por sua vez, já em 1977, foi efectuada uma revisão do regulamento anterior, com o Plano Geral de Urbanização de Lisboa, elaborado pelo arquitecto Meyer-Heine. O objectivo desde regulamento seria enquadrar uma nova realidade urbana, nomeadamente: o aumento do tráfego automóvel, o arranque da rede de metropolitano, a construção da ponte sobre o Tejo, e o início do processo de terciarização do centro e do crescimento dos arredores da cidade.

10 Procurando acompanhar o processo de expansão urbana, o processo de regulação urbana terá assumido uma maior importância à medida que foram sendo atingidos, nas décadas seguintes, elevados níveis de saturação urbana, tendo havido uma necessidade de promover nova revisão do documento normativo vigente, culminando com a publicação, em 1994, do Plano Director Municipal (PDM) actualmente em vigor, mas que por várias razões está actualmente a ser alvo de um processo de revisão. Várias razões têm sido apontadas para a revisão do actual PDM (CML, 1994), destacando-se a falta de planeamento urbano e graves assimetrias estruturais que prevaleceram na cidade de Lisboa, tais como: a dicotomia centro-periferia (a necessitar de uma maior contenção e qualificação das expansões com a revitalização do centro), défices de equipamentos colectivos e de habitação (de forma a minimizar a perda e o envelhecimento da população residente), bem como a ausência de uma eficaz política de mobilidade partindo da integração dos vários modos de transporte e que, em particular, potenciasse os modos de transporte ecológicos (Câmara Municipal de Lisboa, 2008).

\section{A Mobilidade Contemporânea na Área Metropolitana de Lisboa}

11 A Área Metropolitana de Lisboa regista actualmente a maior concentração populacional do país. Esta região, constituída por dezanove concelhos, representando apenas 3,3\% da superfície do território nacional, apresentava em 2001 uma taxa de ocupação de um pouco mais de 1/4 da população portuguesa, 2662949 habitantes, quando em 1960 esta relação que era somente de 1/6 (Tenedório, 2003).

12 A análise da distribuição da população da AML revelou desde logo uma tendência da evolução demográfica metropolitana: a diminuição em termos efectivos do número de residentes na capital, queda que se terá acentuado a partir de 1960, quando residiam no concelho de Lisboa cerca de $52,6 \%$ da população total da AML, um valor já consideravelmente reduzido, comparativamente aos anteriores $72,3 \%$ registados em 1930. Declínio este que nas décadas seguintes se manteve de uma forma gradual, registando-se em 2001 o valor mais baixo, com apenas 20,9\%, cerca de 556797 habitantes (Tenedório, 2003).

13 Para este fenómeno de perda gradual de habitantes da cidade de Lisboa muito terá contribuído a terciarização do centro urbano, o aumento dos preços das habitações e a existência de melhores acessos rodoviários. Da mesma forma que outros, como a expansão da rede viária, terão potenciado o crescimento populacional nas cidades da periferia, promovendo um ainda maior afastamento entre o local de residência e o 
local de trabalho, geralmente associado ao sector dos serviços e maioritariamente localizados no concelho de Lisboa (Salgado, 1999: 105).

Surge assim como inevitável que um maior afastamento entre o local de residência e o local de trabalho terá acarretado não só um acréscimo das necessidades de mobilidade metropolitana, mas também um aumento no tempo despendido nas deslocações diárias dos residentes na AML, com diferenças significativas ao longo do intervalo compreendido entre os 15 minutos e os 90 minutos de tempo diário despendido nas deslocações de casa para o emprego/escola (Xerez, 2008: 11).

Tabela 1 湤 População de várias cidades da AML tendo em conta os indivíduos que trabalham no concelho onde residem e o tempo despendido nas deslocações entre a residência e o local de trabalho

\begin{tabular}{|c|c|c|c|c|}
\hline Centro da AML & \multicolumn{2}{|c|}{ Zona Norte da AML } & \multicolumn{2}{|c|}{ Zona Sul da AML } \\
\hline \multirow{5}{*}{ Lisboa $(87,7 \%)$} & \multicolumn{2}{|l|}{ Amadora $(15,4 \%)$} & \multicolumn{2}{|c|}{ Barreiro $(18,5 \%)$} \\
\hline & \multicolumn{2}{|l|}{ Oeiras $(18,5 \%)$} & \multicolumn{2}{|c|}{ Seixal $(19,4 \%)$} \\
\hline & \multicolumn{2}{|l|}{ Sintra $(23,3 \%)$} & \multicolumn{2}{|c|}{ Almada $(21,3 \%)$} \\
\hline & \multicolumn{2}{|l|}{ Odivelas (16\%) } & \multicolumn{2}{|c|}{ Alcochete (21\%) } \\
\hline & \multicolumn{2}{|l|}{ Loures $(19,9 \%)$} & \multicolumn{2}{|c|}{ Moita (15,8\%) } \\
\hline Tempo despendido & Até 15 minutos & De 16 a 30 & De 31 a 60 & De 61 a 90 \\
\hline Percentagem & $31,9 \%$ & $39,3 \%$ & $18,9 \%$ & $2,5 \%$ \\
\hline
\end{tabular}

Fonte: CARVALHO, F. E F. GOMES (1996).

Tabela 2 鹕 População tendo em conta os níveis de motorização dos agregados familiares da AML

\begin{tabular}{|l|l|l|l|l|l|l|l|}
\hline $\begin{array}{l}\text { A Norte } \\
\text { do Tejo }\end{array}$ & $\begin{array}{l}\text { Sem } \\
\text { Motorização }\end{array}$ & $\begin{array}{l}\text { Com dois ou } \\
\text { veículo }\end{array}$ & $\begin{array}{l}\text { A Sul } \\
\text { do Tejo }\end{array}$ & $\begin{array}{l}\text { Sem } \\
\text { Motorização }\end{array}$ & $\begin{array}{l}\text { Com } \\
\text { véículo }\end{array}$ & $\begin{array}{l}\text { Com dois ou } \\
\text { mais veículos }\end{array}$ \\
\hline Lisboa & $40 \%$ & $44 \%$ & $16 \%$ & Alcochete & $27 \%$ & $46 \%$ & $27 \%$ \\
\hline Amadora & $27 \%$ & $55 \%$ & $18 \%$ & Almada & $27 \%$ & $55 \%$ & $18 \%$ \\
\hline Azambuja & $26 \%$ & $44 \%$ & $30 \%$ & Barreiro & $33 \%$ & $50 \%$ & $17 \%$ \\
\hline Cascais & $19 \%$ & $47 \%$ & $34 \%$ & Moita & $28 \%$ & $50 \%$ & $22 \%$ \\
\hline Loures & $27 \%$ & $55 \%$ & $18 \%$ & Montijo & $20 \%$ & $45 \%$ & $35 \%$ \\
\hline Mafra & $21 \%$ & $44 \%$ & $35 \%$ & Palmela & $16 \%$ & $50 \%$ & $34 \%$ \\
\hline Oeiras & $23 \%$ & $48 \%$ & $29 \%$ & Seixal & $25 \%$ & $55 \%$ & $20 \%$ \\
\hline
\end{tabular}




\begin{tabular}{|l|l|l|l|l|l|l|l|}
\hline Sintra & $18 \%$ & $51 \%$ & $31 \%$ & Sesimbra & $22 \%$ & $44 \%$ & $34 \%$ \\
\hline $\begin{array}{l}\text { Vila F. } \\
\text { de Xira }\end{array}$ & $20 \%$ & $61 \%$ & $19 \%$ & Setúbal & $23 \%$ & $51 \%$ & $26 \%$ \\
\hline
\end{tabular}

FONTE: Inquéritos Gerais à Mobilidade, 1996.

Neste contexto específico, de aumento acentuado da procura de meios de transporte essenciais para as deslocações diárias num contexto de mobilidade metropolitana pendular, e face à insuficiente resposta dos operadores públicos/privados de transportes colectivos, tem havido nas últimas décadas um acréscimo significativo dos níveis de motorização dos agregados familiares desta região, assim como do número médio de viagens diárias com recurso ao automóvel particular realizadas pelos habitantes da Área Metropolitana de Lisboa.

Neste âmbito importará salientar o facto de que numa elevada percentagem de famílias residentes em Lisboa não foi identificada qualquer motorização, por outro, em concelhos como Cascais, Mafra, Sintra, Montijo, Palmela e Sesimbra registaram-se percentagens elevadas de famílias com dupla motorização. Quanto à contabilização do número médio de viagens realizadas por dia, os estudos apresentam um panorama significativamente distinto. Localidades como Mafra, Alcochete e Montijo apresentaram um número médio de 2,4 viagens por dia, enquanto em Cascais e Moita o valor registado foi mais elevado (2,9 viagens por dia), tendo sido identificado que em cerca de $14 \%$ do total da amostra foram realizadas mais de 4 viagens por dia (Carvalho e Gomes, 1996).

\section{A mobilidade urbana em Lisboa: Os padrões de mobilidade pendular e as infra-estruturas de transporte rodoviário em Lisboa}

Os elevados níveis de motorização das famílias residentes nos vários concelhos da AML e a utilização predominante do veículo automóvel nas deslocações pendulares diárias poderão ter produzido impactos directos em determinadas zonas da capital portuguesa, mais acentuados em locais com elevados índices de viagens a pé. Neste aspecto consideramos que a área da Baixa tem assumido nas últimas décadas um papel ímpar, já que registará um dos valores mais elevados ao nível dos movimentos pedonais em toda a AML (mais de 135000 viagens pedonais por dia). Este valor corresponderá actualmente a mais de $8 \%$ do total de viagens apuradas em todo o concelho de Lisboa, sendo que apenas $37 \%$ destas viagens serão realizadas por residentes no concelho, e as restantes $67 \%$ serão realizadas por pessoas que residem nos restantes concelhos da AML (CML, 2008).

Do ponto de vista da mobilidade urbana as deslocações no centro da cidade de Lisboa são caracterizadas por uma inevitável partilha de um espaço rodoviário particularmente congestionado. Veja-se como exemplo a Praça do Comércio onde circulam cerca de 5500 veículos/hora nas horas de maior congestionamento rodoviário, ou seja, 65000 veículos no período compreendido entre as $07 \mathrm{H} 00$ e as $21 \mathrm{H} 00$, sendo que em aproximadamente $76 \%$ dos veículos a circular naquela área da cidade é identificado 
o movimento de atravessamento (não constituindo o destino final da viagem dos utilizadores), e que $42 \%$ do total destas viagens constituem deslocações para o emprego (CML, 2008).

19 Face a um inevitável acréscimo de veículos automóveis na cidade de Lisboa, as políticas públicas de reabilitação das zonas da cidade mais afectadas ${ }^{5}$ têm procurado combater os elevados índices de poluição e de ruído que se registam actualmente no centro da cidade, já que, a manterem-se os padrões actuais de circulação automóvel, é expectável que o número de veículos a circular nos bairros e no centro da cidade atinja valores acima do tolerável e crie necessariamente ainda mais conflitos entre peões e veículos, bem como um incremento da taxa de sinistralidade pedonal.

Esta situação é já hoje bastante acentuada na área baixa da cidade de Lisboa, um local paradigmático da capital portuguesa que reúne um conjunto de características de mobilidade muito específicas. A elevada intensidade de tráfego registada na Avenida 24 de Julho e Avenida Infante D. Henrique, vias concebidas para um modelo de mobilidade urbana e interurbana numa cidade fordista (Jessop, 1992), poderá estar na origem do elevado índice de atropelamentos que estas vias apresentaram no período estudado. Complementarmente, tem-se assistido nas últimas décadas a uma alteração nos padrões de consumo, ou seja, uma procura acrescida de infra-estruturas ligadas ao lazer e à diversão por parte das populações urbanas da AML (Salgado, 1999: 105). Desta forma, definiu-se como objectivo principal deste estudo a promoção de uma análise das principais características dos acidentes de viação com utentes pedonais ocorridos nesta área da cidade de Lisboa, procurando aferir a influência nestes eventos específicos de condicionantes estruturais como a reorganização dos padrões de mobilidade (pendularidade metropolitana), o crescimento de actividades económicas ligadas ao lazer nocturno, os novos padrões de consumo e comportamentos de risco associados à diversão nocturna.

Para este efeito promoveu-se a análise de todos os atropelamentos com vítimas graves e mortais, ocorridos na área em estudo no período compreendido entre 2006 e 2009, procurando-se desta forma verificar se nestas circunstâncias específicas se replicavam as tendências registadas em estudos anteriores para a totalidade do concelho de Lisboa (Meirinhos, 2010). Pretendia-se com a interpretação destes resultados lançar as bases para uma futura análise de uma correlação estatística entre os fenómenos descritos (mobilidade, acessibilidade e sinistralidade), esperando-se numa primeira fase, ao efectuar uma descrição dos resultados, identificar potenciais pontos de conflito pedonal nesta área da capital. Para este efeito promoveu-se uma análise epidemiológica dos padrões de sinistralidade pedonal localizada na área em estudo (ver mapa seguinte), com recurso a ferramentas SIG, e tendo por base as estatísticas dos acidentes de viação envolvendo peões cedidas pela Polícia de Segurança Pública de Lisboa para os anos de 2006 a 2009.

22 Analisando a distribuição dos atropelamentos no eixo viário, com cerca de 12,9 km, que se estende desde a Avenida Infante D. Henrique, passando pela Avenida 24 de Julho e pela Avenida da Índia, foi possível verificar que entre os anos de 2006 e 2009 houve uma elevada incidência de atropelamentos ${ }^{6}$ naquele local, tendo em conta o total do concelho de Lisboa (cerca de $11 \%$ do total de feridos graves por atropelamento em Lisboa e cerca de $28 \%$ do total de mortes por atropelamento em Lisboa). Foi ainda possível verificar nesta zona da baixa da cidade a existência de uma elevada incidência deste tipo de acidentes na Av. 24 de Julho e na Av. Infante D. Henrique. No total, estas 
duas vias apresentaram 27 feridos graves ( $84 \%$ do total de vítimas do eixo viário) e 4 vítimas mortais (44\%).

Mapa 1 粮 Mapa de atropelamentos no eixo rodoviário em análise (2006-2009)

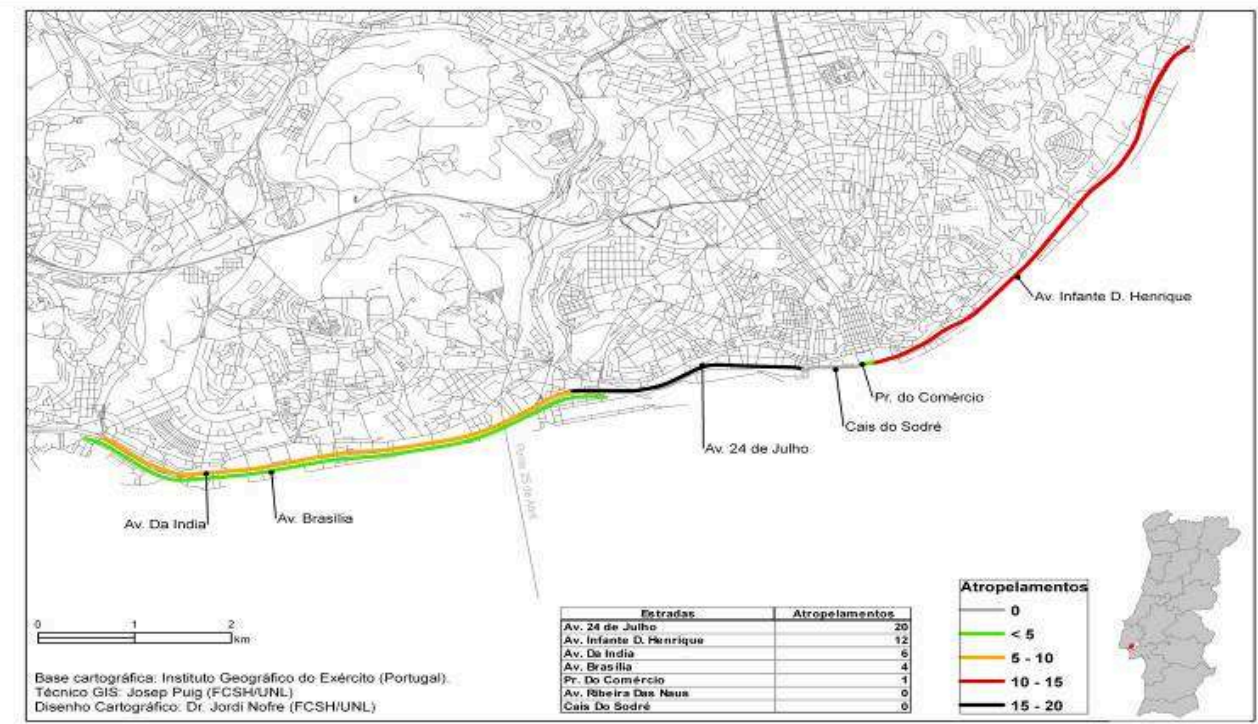

\section{A - Estudo de caso: Avenida Infante D. Henrique}

Tendo em conta as características do tráfego automóvel regista-se que, em hora de ponta, a área da Baixa de Lisboa é utilizada por cerca de 6100 veículos/hora, no período da manhã, e 6600 no período da tarde. Do total, cerca de metade utilizam a Av. Infante D. Henrique ou a Av. 24 de Julho, enquanto cerca de $25 \%$ utilizam ambas as vias, ou seja, percorrem todo o arco ribeirinho (Silva, 2009: 16). Tratando-se de um dos locais da cidade com maior índice de circulação automóvel, interessava promover um estudo desta Avenida (troço de 5,3 km) através da análise das estatísticas de sinistralidade rodoviária. Para este efeito foram analisados os dados epidemiológicos de todos os atropelamentos contabilizados pela Polícia de Segurança Pública (registados nos Boletins Estatísticos de Acidentes de Viação - BEAV) durante os anos de 2006 a 2009, no total de 12 casos, distribuídos de acordo com a seguinte tabela:

Tabela 3 疄 Vítimas de atropelamento (feridos graves e vítimas mortais) na Avenida Infante D. Henrique, no período 2006 a 2009

\begin{tabular}{|l|l|l|l|l|l|}
\hline Ano & 2006 & 2007 & 2008 & 2009 & Total \\
\hline $\begin{array}{l}\text { Feridos } \\
\text { Graves }\end{array}$ & 3 & 2 & 2 & 3 & 10 \\
\hline $\begin{array}{l}\text { Vítimas } \\
\text { Mortais }\end{array}$ & 0 & 2 & 0 & 0 & 2 \\
\hline
\end{tabular}

FONTE: Polícia de Segurança Pública, 2010. 
O estudo da distribuição dos atropelamentos no período em análise revelou desde logo uma tendência oposta à verificada nos dados englobando todo o concelho (uma elevada representatividade destes eventos durante os dias da semana e durante as horas de ponta da manhã e da tarde). De facto, nesta área da cidade constatou-se a existência de um elevado número de atropelamentos nos períodos de fim-de-semana, mais precisamente às sextas-feiras e sábados, períodos que, não estando directamente relacionados com os períodos de maior intensidade de tráfico, poderiam advir de uma maior disponibilização neste período de actividades ligadas ao lazer das populações residentes na cidade de Lisboa bem como em toda a AML.

Mapa 2 [F⿻

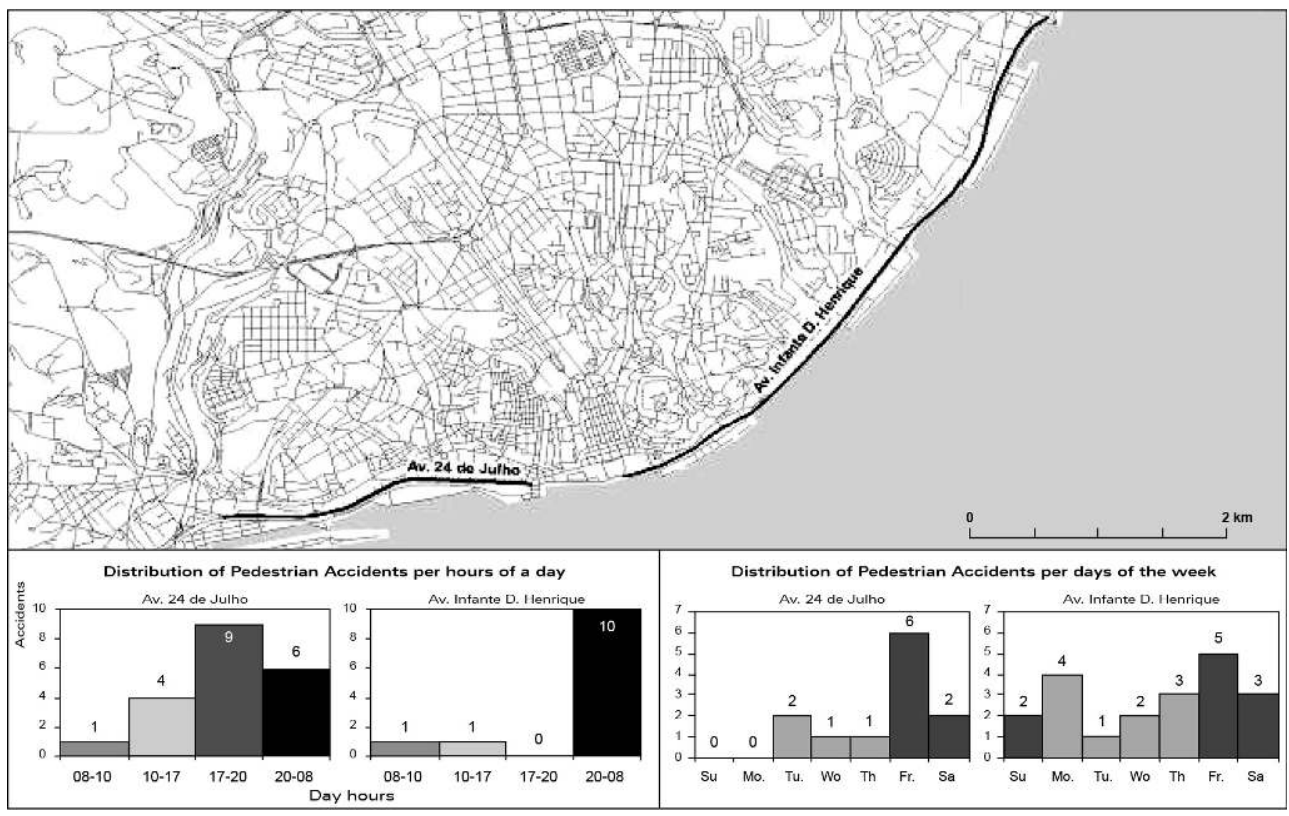

Perante os dados apurados neste local e a diferença registada com o total do concelho, importava desde logo averiguar uma possível associação entre a ocorrência de atropelamentos e uma elevada representatividade de actividades relacionadas com a diversão nocturna, pelo que terá sido determinante observar neste período de quatro anos uma elevada representatividade de vítimas por atropelamento ocorrido no período nocturno (entre as $20 \mathrm{H} 00$ e as $08 \mathrm{H} 00$ ), representando cerca de $75 \%$ do total de vítimas para o período estudado, havendo uma distribuição homogénea nos restantes períodos do dia (8,3\%). No tocante à distribuição de vítimas por género, os resultados evidenciaram uma maior representatividade do masculino (58,3\%) enquanto o feminino representou $41,7 \%$ do total de casos analisados. Desta forma, e à semelhança dos padrões anteriores (dia da semana e hora do dia), verificou-se uma redistribuição de vítimas por género diferente do enunciado para o total do concelho de Lisboa, em que registou uma maior prevalência do género feminino e no grupo etário com mais de 69 anos de idade (37\% em 2008), tendência que não se evidenciou na presente análise, conforme descrito na seguinte tabela: 


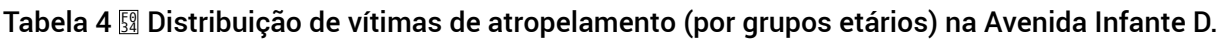
Henrique, no período 2006 a 2009

\begin{tabular}{|l|l|l|l|l|l|l|l|}
\hline Grupo Etário & $20-29$ & $30-39$ & $40-49$ & $50-59$ & $60-69$ & +69 & Total \\
\hline № de Casos & 2 & 1 & 4 & 2 & 2 & 1 & 12 \\
\hline
\end{tabular}

FONTE: Polícia de Segurança Pública, 2010.

Neste caso específico, a distribuição de casos de atropelamento por grupo etário exibiu uma maior incidência de ocorrências no escalão dos 40 aos 49 anos de idade, 4 em 12, ou seja, 33,3\% do total de vítimas. Seguindo-se os grupos dos 20 aos 29 anos, dos 50 aos 59 anos, bem como dos 59 aos 69 anos com cerca de 16,7\% para cada escalão mencionado.

\section{B - Estudo de caso: Avenida 24 de Julho}

Numa segunda etapa de análise foi efectuada uma descrição de todos os dados epidemiológicos relativos aos atropelamentos de peões na via rodoviária com o maior índice de sinistralidade pedonal em todo o eixo viário da zona ribeirinha de Lisboa. A importância do estudo deste eixo viário teria nesta fase duas finalidades distintas. Numa primeira etapa confirmar a existência de um padrão de atropelamentos semelhante ao identificado no estudo de caso anterior, a Avenida Infante D. Henrique, o que numa segunda etapa iria permitir distanciar os resultados obtidos neste local da baixa da cidade dos resultados previamente apurados para o total do concelho de Lisboa.

Com efeito, a Avenida 24 de Julho, que se estende ao longo de $2,4 \mathrm{~km}$, apresentou o maior índice de atropelamentos (cerca de 9 vítimas $/ \mathrm{km}$ ), 46,5\% do total de acidentes com peões registados nos anos de 2006 a 2009 em todo o eixo (no total de 12,9 km). Ao contrário do que se verificou no estudo da Avenida Infante D. Henrique, a Avenida 24 de Julho apresentou uma diminuição da fatalidade por atropelamento nos anos $2008 \mathrm{e}$ 2009. Sendo no entanto de ressalvar a inexistência de dados relativos à contabilização de mortos a trinta dias (um mecanismo que só veio a ser implementado em data posterior a esta análise, seguindo o normativo da Comissão Europeia).

Tabela 5 [5is Distribuição de vítimas de atropelamento (feridos graves e vítimas mortais) na Avenida 24 de Julho, no período de 2006 a 2009

\begin{tabular}{|l|l|l|l|l|l|}
\hline Ano & 2006 & 2007 & 2008 & 2009 & Total \\
\hline Feridos Graves & 7 & 2 & 4 & 5 & 18 \\
\hline Vítimas Mortais & 1 & 1 & 0 & 0 & 2 \\
\hline
\end{tabular}

FONTE: Polícia de Segurança Pública, 2010.

Foi possível notar algumas diferenças nos dados epidemiológicos da Avenida 24 de Julho, comparativamente ao estudo anterior onde se verificou uma elevada concentração de vítimas nos períodos nocturnos e nos fins-de-semana. De facto, na presente via, a distribuição de vítimas por dias da semana revelou uma maior 
concentração de atropelamentos às segundas e sextas-feiras (ambas com 20\% do total para esta via) seguindo-se os domingos, quintas-feiras e sábados (com $15 \%$ em cada).

Já a distribuição dos atropelamentos por períodos do dia apresentou uma distribuição uniforme nos anos 2006, 2007 e 2009, com uma elevada concentração de vítimas (30\%) no período das $20 \mathrm{H} 00$ às $08 \mathrm{H} 00$. É no entanto de referir que na Av. 24 de Julho, ao contrário do que se verificou na Av. Infante D. Henrique, o pico de ocorrências de atropelamento (45\%) foi identificado na hora ponta tarde (17H00-20H00). Por sua vez a distribuição por género, exibiu uma maior representatividade do género masculino (65\% do total de vítimas), distribuindo-se pelo género feminino os restantes $35 \%$, tendência que se manteve durante os anos 2006, 2007 e 2009, com excepção de 2008, ano em que se registou uma percentagem igual para ambos os géneros.

Por último, na distribuição etária das vítimas, observou-se uma maior incidência nos grupos dos 30-39 anos e no grupo com mais de 69 anos, ambos com 4 casos em 20 . Ou seja, registando-se em cada um destes grupos etários $20 \%$ do total. Os restantes casos foram dispersos ${ }^{8}$ pelos restantes grupos etários, conforme se pode observar na Tabela 6 .

Tabela 6 [0. 2006 a 2009

\begin{tabular}{|l|l|l|l|l|l|l|l|l|l|}
\hline Grupo Etário & Nulo & $10-19$ & $20-29$ & $30-39$ & $40-49$ & $50-59$ & $60-69$ & +69 & Total \\
\hline № de Casos & 1 & 3 & 1 & 4 & 3 & 3 & 1 & 4 & 20 \\
\hline
\end{tabular}

FONTE: Polícia de Segurança Pública, 2010.

Independentemente do facto de os dados analisados permitirem aferir a evolução da sinistralidade apenas num curto período de tempo (de 2006 a 2009), os objectivos deste estudo seriam promover uma análise primária das principais características dos atropelamentos com gravidade, ocorridos nas duas principais vias do eixo viário em análise (que não só apresentam o mais elevado índice de fatalidade pedonal na cidade de Lisboa, como um dos mais elevados índices de circulação automóvel), e dos quais resultaram vítimas mortais ou com ferimentos graves, bem como estabelecer uma comparação com os resultados apurados através da realização de estudos prévios para todo o concelho de Lisboa (Meirinhos, 2009; 2010). Estamos certos que para além destas vítimas que sofreram danos severos, e até mesmo mortais, existirão muitas outras que diariamente serão afectadas com menor gravidade um pouco por toda a cidade de Lisboa, profundamente motorizada e na qual se movimentam diariamente milhões de cidadãos e de veículos partilhando um espaço comum mas por vezes inóspito aos que andam a pé.

\section{Conclusão}

Para John Urry (2002), a necessidade de mobilidade das sociedades não poderá ser dissociada do fenómeno global da motorização. De tal forma que a associação desta exigência a um simples objecto de consumo, o automóvel, produziu transformações nos conceitos de tempo, espaço e velocidade, dando origem a modificações profundas ao nível da organização das sociedades e naturalmente da própria geografia terrestre 
(Urry, 2002). Considerar-se-á, no entanto, que grande parte do sucesso do automóvel, quando comparado com o transporte colectivo, se deverá ao carácter individual associado a este meio de transporte (Sheller, 2004: 222), que constitui um elemento dinamizador do modelo de mobilidade pendular que caracteriza a Área Metropolitana de Lisboa. Registam-se contudo no crescimento de toda a região metropolitana algumas particularidades no decurso das últimas décadas: diferenças do nível de desenvolvimento e disponibilização de infra-estruturas registadas entre o centro e a periferia metropolitana, envelhecimento e perda de população residente na capital para as periferias e concelhos limítrofes, elevados índices de poluição associados ao congestionamento de trânsito (perceptíveis em vários locais da cidade de Lisboa), bem como elevados níveis de sinistralidade rodoviária (sobretudo pedonal). Estes constituem os principais factores apontados para o actual processo de revisão do Plano Director Municipal em vigor desde 1994 (CML, 2008).

34 Face a um elevado índice de motorização da população residente nos concelhos da região metropolitana (exceptuando-se Lisboa), será de salientar uma primeira tendência que se tem vindo a acentuar nas últimas décadas ao nível das deslocações dos residentes na AML, a diminuição de viagens realizadas com recurso aos transportes públicos seguida de muito perto pela duplicação dos utilizadores de transportes individuais, padrões que estarão na base do actual modelo de mobilidade pendular existente na Área Metropolitana de Lisboa, desconhecendo-se, no entanto, os efeitos na população do elevado volume de tráfego automóvel em locais caracterizados por um elevado número de viagens a pé, mais especificamente nos pontos de conflito entre utentes rodoviários (Meirinhos, 2011). Neste aspecto consideramos que a área da baixa da cidade de Lisboa apresenta características únicas dentro da capital e da própria AML, não só pelo elevado índice de circulação pedonal e automóvel nesta zona da cidade, mas também pelos valores elevados ao nível da fatalidade por atropelamentos de peões (cerca de $28 \%$ de mortes registadas em todo o concelho). Partindo do mesmo pressuposto (elevada fatalidade pedonal), foram analisadas duas rodovias estruturais no mapa viário da capital, mormente pelo seu papel determinante de confluência de acessos metropolitanos à cidade de Lisboa e elevada representatividade de interfaces de transportes públicos, a Avenida Infante D. Henrique e a Avenida 24 de Julho, que em conjunto representaram $84 \%$ de feridos graves e $44 \%$ de vítimas mortais do total registado em todo o eixo ribeirinho que se prolonga ao longo de $12,9 \mathrm{~km}$. Os dados estatísticos de sinistralidade demonstraram três características principais. Em primeiro lugar, uma concentração dos atropelamentos no final da tarde e noite, e principalmente no fim-de-semana (incluindo a sexta-feira). Em segundo lugar, os dados indicam uma prevalência de vítimas do sexo masculino, predominantemente no grupo etário dos 30 aos 49 anos, tendo sido aferida uma idade média de 41 anos. Por último, uma tendência para a diminuição efectiva de atropelamentos resultando em feridos graves e vítimas mortais no período estudado e em todo o eixo viário, sendo de destacar, no entanto, que essa tendência foi interrompida em 2009, ano em que, segundo os dados estatísticos, se registou um aumento generalizado do número de vítimas em todo o concelho de Lisboa, bem como no eixo rodoviário analisado.

Neste aspecto será importante salientar que, ao contrário do evidenciado em estudos anteriores (Meirinhos, 2009; 2010), os fluxos rodoviários com maior intensidade (horas de ponta manhã e tarde) não coincidiram, de acordo com os dados registados, com os períodos do dia e da semana em que ocorreram um maior número de atropelamentos 
com gravidade. Face a estes resultados, será de considerar a hipótese de que uma maior incidência de vítimas no período nocturno e aos fins-de-semana poderá indiciar uma associação da fatalidade por atropelamento à disponibilização no local de inúmeros estabelecimentos de diversão nocturna, hipótese a ser explorada em estudos futuros com o apoio de diferentes ferramentas de tecnologia de informação geográfica.

\section{BIBLIOGRAFIA}

ANSR (2009), Estratégia Nacional para a Segurança Rodoviária. Aprovada em Resolução do Conselho de Ministros n.․ 54/2009 (de 26 de Junho), pp. 4160-4188.

BAPTISTA, L. e J. Nunes (2004), “O contexto metropolitano e (re)classificação urbana: apontamentos sobre a cidade de Lisboa e um bairro na sua periferia." Ciudades, 8, pp. 87-100.

CARVALHO, F. e F. Gomes (1996), Inquéritos gerais à mobilidade: os casos de Porto e Lisboa. Alguns indicadores de mobilidade, III Congresso Português de Sociologia, Oeiras, APS/Celta Editora.

CML (1994), Plano Director Municipal, Lisboa.

CML (2008), Conceito de Circulação para a Frente Tejo, entre Santa Apolónia e Cais do Sodré, Lisboa, Câmara Municipal de Lisboa.

DARGAY, J. e D. Gately (1998), “Income's effect on car and vehicle ownership worldwide: 1960-2015”, Journal of Transport, Economics and Policy, 33 (2), pp. 101-138.

EUROPEAN COMMISSION (2010), European Road Safety Action Programme 2011-2020, European Commission, Brussels.

FREUND, P. e G. Martin (2007), “Hyperautomobility, the social organization of space and health", Mobilities, 2 (1), pp. 37-49.

JESSOP, B. (1992). "Fordism and Post-Fordism: A critical reformulation", in A. Scott e M. Storper (eds.), Pathways to Industrialization and Regional Development, Londres, Routledge.

LUSOPONTE/GESTIPONTE (2010), Distribuição de utentes das travessias rodoviárias sobre o rio Tejo (2006-2009), Lisboa, Lusoponte/Gestiponte.

MEIRINHOS, V. (2009), Pedonalidade em risco: Estudo antropológico dos atropelamentos em Lisboa, Departamento de Antropologia, Lisboa, ISCTE-IUL. MA: 96.

MEIRINHOS, V. (2010), “The walker and Lisbon: an epidemiological study of road accidents involving pedestrians in Lisbon in 2006 and 2007", in M. Ramos e M. Alves, The walker and the city, Lisboa, Associação de Cidadãos Auto-Mobilizados, p. 234.

MEIRINHOS, V. (2011), "Risco e atribuição: representações dos atropelamentos em Lisboa”, in M. Ramos, Risco e Trauma nas Estradas Portuguesas, Lisboa, Associação de Cidadãos Auto-Mobilizados, p. 222.

MERRIMAN, P. (2009), “Automobility and the Geographies of the Car”, Geography Compass, 3/2, pp. 586-599.

PSP (2010), Dados estatísticos de sinistralidade rodoviária em Lisboa nos anos 2006 a 2009, Lisboa, PSP. 
SALGADO, M. (1999), "Lisboa. O rio e a renovação urbana, Expo'98. O seu papel como catalisador do rejuvenescimiento de Lisboa”, Ciudades, 5, pp. 103-113.

SALGUEIRO, T. (1997), “Lisboa, metrópole policêntrica e fragmentada”, Finisterra, XXXII (63), pp. 179-190.

SCHAFER, A. e D. Victor (2000), "The future mobility of the world population", Transport Research Part A, 34, pp. 171-205.

SERDOURA, F. (2008), “A emergência de novas centralidades: o caso de lisboa”, Minerva, 5 (2), pp. 187-196.

SHELLER, M. (2004), “Automotive emotions”, Theory, Culture \& Society, 21 (4/5), pp. 221-242.

SHELLER, M. e J. Urry (2000), “The city and the car”, International Journal of Urban and Regional Research, 24, pp. 737-757.

SILVA, F. (2009), Avaliação dos impactes da interrupção da circulação automóvel na Baixa e Praça do Comércio, Lisboa, Centro de Sistemas Urbanos e Regionais - Núcleo de Urbanismo e Ambiente, pp. $1-46$.

TEIXEIRA, M. (1993), “A história urbana em Portugal. desenvolvimentos recentes”, Análise Social, XXVIII (121), pp. 371-390.

TENEDÓRIO, J. (ed.) (2003), Atlas da Área Metropolitana de Lisboa, Lisboa, Área Metropolitana de Lisboa.

TRANSTEJO/SOFLUSA (2010), Volume anual de passageiros transportados em transporte colectivo fluvial (2006-2009), Lisboa, Transtejo/Soflusa.

URRY, J. (2002), “Mobility and proximity”, Sociology, 36 (2), pp. 255-274.

VILHELMSON, B. (1999), "Daily mobility and the use of time for different activities. The case of Sweden”, GeoJournal, 48, pp. 177-185.

XEREZ, R. (2008), “Dinâmicas do Território: centralidades e gentrificação na Área Metropolitana de Lisboa”, VI Congresso Português de Sociologia. Mundos Sociais: Saberes e Práticas, Lisboa, Universidade Nova de Lisboa, Faculdade de Ciências Sociais e Humanas.

\section{NOTAS}

1. Com excepção da Roménia e de Malta, cujas estatísticas de sinistralidade sofreram um incremento de $14 \%$ e $31 \%$ respectivamente no período compreendido entre 2001-2009 (European Comission, 2010).

2. Para Mimi Sheller e John Urry (2000), os impactos da excessiva de motorização nas sociedades contemporâneas manifestam-se, entre outros aspectos, através da segregação no seio das comunidades urbanas, nomeadamente ao nível dos acessos a infra-estruturas básicas (Sheller e Urry, 2000: 739)

3. Em Lisboa, são realizados diariamente cerca de 2,3 milhões de viagens com pelo menos um extremo dentro do seu perímetro (Colecção de Estudos Urbanos - Lisboa XXI - 7 da Câmara Municipal de Lisboa).

4. Dados oficiais fornecidos pela Polícia de Segurança Pública de Lisboa, registados com base nas participações de acidentes por atropelamento reportados às autoridades policiais.

5. A Proposta 1222/2008 da CML - "Plano de Mobilidade para a Baixa", previa a separação do transporte individual do transporte público junto da frente ribeirinha da cidade de Lisboa. 
6. Para o efeito foram analisadas todas as ocorrências por atropelamento ocorridas no período compreendido entre 2006 e 2009 na zona da Baixa de Lisboa (constituído pela Avenida Infante D. Henrique, a Avenida 24 de Julho, a Avenida de Brasília, a Praça do Comércio e a Avenida da Índia). 7. Do ponto de vista metodológico, para a análise da distribuição ao longo do dia foram considerados quatro períodos diários: hora ponta manhã (08H00-10H00); período diurno (10H00-17H00); hora ponta tarde (17H00-20H00) e período nocturno (20H00-08H00).

8. Do ponto de vista da metodologia, importará registar um valor nulo relativamente à idade de uma vítima de atropelamento na Avenida 24 de Julho (ver Tabela 6).

\section{RESUMOS}

A utilização individual e recorrente do automóvel particular nas sociedades contemporâneas tem promovido uma elevada fragmentação das comunidades locais bem como impactos directos na saúde pública das populações. Perante a inevitabilidade destes fenómenos tem havido forte aposta das autoridades europeias na segurança rodoviária. Neste aspecto, poderá ser considerado paradigmático o caso da baixa da cidade de Lisboa, um local de confluência dos principais movimentos pendulares de acesso à cidade de Lisboa. Perante estes resultados será de propor que a elevada sinistralidade pedonal no período em análise possa de alguma forma estar correlacionada com a elevada concentração de estabelecimentos de diversão nocturna. 0 presente estudo promove uma análise epidemiológica dos atropelamentos ocorridos na baixa da cidade de Lisboa, num período de quatro anos (2006-2009), de forma a aferir a influência de determinados aspectos estruturais característicos daquela área emblemática da cidade de Lisboa.

The individual use of private vehicles is rapidly increasing in post-Fordist cities, promoting the excessive fragmentation of local communities and producing immediate impacts on public health. In 2008 more than 37,000 deaths were recorded as a result of road accidents in the U.S. and over 39,000 in the European Union. That is why road safety is currently a matter of crucial concern throughout Europe, and is therefore considered a priority area of intervention by the European Commission. In the case of the city of Lisbon (Portugal), the riverfront constitutes a place of confluence for major road infrastructures considered essential to everyday metropolitan mobility not only during the daytime, but also at night. This may lead us to hypothesize that the verified elevated number of accidents (involving not only vehicles, but also pedestrians) is directly related to several structural factors that together characterize the area of downtown Lisbon. The present study analyzes traffic accidents in this area of the Portuguese capital by providing a detailed statistical analysis and a thorough geo-referenced representation of all of the accidents involving pedestrians within this area using geographic information referring to the years from 2006 to 2009 .

\section{ÍNDICE}

Palabras claves: road accidents, pedestrian safety, road design, leisure activities

Palavras-chave: sinistralidade rodoviária, pedonalidade, mobilidade urbana, lazer noturno 


\section{AUTOR}

\section{VICTOR MEIRINHOS}

Doutorando em Antropologia na FCSH-UNL/CesNova e Docente do ICPOL-ISCPSI

victormeirinhos@fcsh.unl.pt 